\title{
Discovery of New Nucleo Cytoplasmic Large Deoxiriboviruses by Transmission Electron Microscopy
}

\author{
A.P. Alves de Matos $^{1,2}$, M.F. Caeiro ${ }^{2}$, Rachel E. Marschang ${ }^{3}$ and Ilan Paperna ${ }^{4}$ \\ 1. Centro de Investigação Interdisciplinar Egas Moniz (CiiEM), Quinta da Granja, Monte de Caparica, \\ 2829-511 Caparica, Portugal. \\ 2. Centro de Estudos do Ambiente e do Mar (CESAM/FCUL), Faculdade de Ciências da Universidade \\ de Lisboa, Campo Grande, 1749-016 Lisboa, Portugal \\ ${ }^{3 .}$ Laboklin GmbH \& Co. KG, Bad Kissingen, Germany. \\ 4. Department of Animal Sciences, Faculty of Agricultural, Food and Environmental Quality Sciences of \\ the Hebrew University of Jerusalem, Rehovot 76100, Israel.
}

The nucleo cytoplasmic large DNA virus (NCLDV) superfamily encompasses a diverse group of large DNA viruses that infect a wide range of eukaryotic hosts [1] and is believed to be monophyletic [2]. Most of these viruses were discovered by electron microscopic detection of the particles in the infected hosts, and were once included in the now abandoned Icosahedral cytoplasmic deoxyribovirus group (ICDV), whose definition depended strongly on the ultrastructural features of the virions [3]. Although several of these viruses could be characterized at the molecular level, many of the particles observed by TEM still defy molecular characterization and may conceal important information regarding the biology of these viruses.

Furthermore, many of the viruses once thought to be only weakly pathogenic turned out to be highly pathogenic for susceptible hosts, but well adapted to their natural hosts. Several well known examples can be found in the smallpox virus, African swine fever virus or the ranaviruses [4].

In this presentation we report on our experience with the identification of new viruses from the NCLDVs, demonstrating the value of transmission electron microscopy for virus discovery.

Our work detected NCLDVs infecting erythrocytes in 14 new species of heterothermic vertebrates and suggested the group as new genus within the Iridoviridae family [5,6]. New European ranaviruses infecting lizards and amphibians were discovered, disclosing their potential danger to aquaculture facilities [6,7]. A new mimivirus-like particle was observed in amoebae from a Lisbon hospital.

\section{References}

[1] J Filée, Current Opinion in Virology 3 (2013), p. 595.

[2] LM Iyer et al, Virus Res 117 (2006), p. 156.

[3] G Devauchelle, DB Stoltz and F Darcy-Tripier, Curr Top Microbiol Immunol 116 (1985) p. 1.

[4] T Williams, , V Barbosa-Solomieu and VG Chinchar, Advances in Virus Research, 65 (2005) p. 173. 
[5] AP Alves de Matos and I Paperna, Ann Parasitol Hum Comp 68 (1993) p. 24.

[6] AP Alves de Matos et al, Microsc Microanal 17 (2011) p. 101.

[7] C Soares et al, Froglog 56 (2003) p. 1.
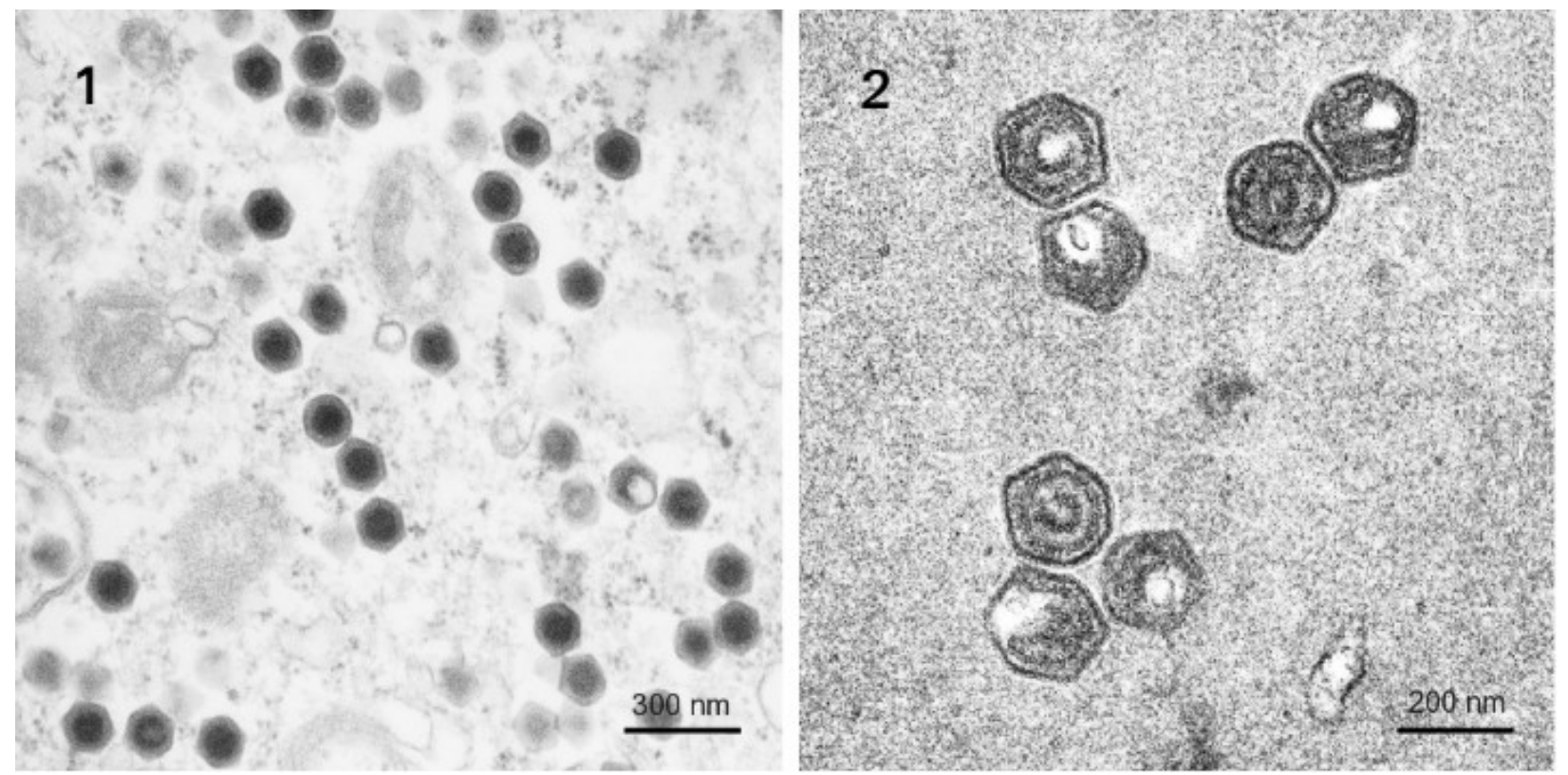

Figure 1. Ranaviruses of Testudo hermanni ranavirus, Switzerland.

Figure 2. Lizard erythrocytic viruses of Lacerta Monticola, Serra da Estrela, Portugal. 